\title{
A genetic association study between growth differentiation factor 5 (GDF 5) polymorphism and knee osteoarthritis in Thai population
}

Tulyapruek Tawonsawatruk ${ }^{*}$, Theeraroj Changthong ${ }^{1}$, Sarinee Pingsuthiwong ${ }^{2}$, Objoon Trachoo², Thanyachai Sura ${ }^{2}$ and Wiwat Wajanavisit ${ }^{1}$

\begin{abstract}
Objective: Osteoarthritis $(\mathrm{OA})$ is a multi-factorial disease and genetic factor is one of the important etiologic risk factors. Various genetic polymorphisms have been elucidated that they might be associated with OA. Recently, several studies have shown an association between Growth Differentiation Factor 5(GDF5) polymorphism and knee OA. However, the role of genetic predisposing factor in each ethnic group cannot be replicated to all, with conflicting data in the literatures. Therefore, the aim of this study was to investigate the association between GDF5 polymorphism and knee OA in Thai population.
\end{abstract}

Materials and Methods: One hundred and ninety three patients aged 54-88 years who attended Ramathibodi Hospital were enrolled. Ninety cases with knee OA according to American College of Rheumatology criteria and one hundred and three cases in control group gave informed consent. Blood sample $(5 \mathrm{ml})$ were collected for identification of GDF5 (rs 143383) single nucleotide polymorphism by PCR/RFLP according to a standard protocol. This study protocol was approved by the Ethics Committee on human experimentation of Ramathibodi Hospital Faculty of Medicine, Mahidol University. Odds ratios (OR) and 95\% confidence intervals were calculated for the risk of knee OA by genotype (TT, TC and CC) and allele (T/C) analyses.

Results: The baseline characteristics between two groups including job, smoking and activity were not different, except age and BMI. The entire cases and controls were in Hardy-Weinberg equilibrium $(p>0.05)$. The OA knee group $(n=90)$ had genotypic figure which has shown by $\Pi 42.2 \%(n=38)$, TC $45.6 \%(n=41)$ and CC $12 \%(n=11)$, whereas the control group $(n=103)$ revealed TT 32\% $(n=33)$, TC 45.6\% $(n=47)$, and CC 22.3\% $(n=23)$, respectively. Genotypic $\Pi$ increased risk of knee $\mathrm{OA}$ as compared to $\mathrm{CC}[\mathrm{OR}=2.41(\mathrm{P}=0.04,95 \% \mathrm{Cl}=1.02-5.67)]$. In the allele analysis, the $\mathrm{T}$ allele was found to be significantly associated with knee $O A[O R=1.53(P=0.043,95 \% C l=1.01-2.30)]$.

Conclusion: These data suggested that GDF5 polymorphism has an association with knee OA in Thai ethnic. This finding also supports the hypothesis that OA has an important genetic component in its etiology, and GDF5 protein might play important role in the pathophysiology of the disease.

Keywords: Osteoarthritis, Growth Differentiation Factor 5, GDF5, SNP, RFLP, Thais

\section{Introduction}

It is widely believed that osteoarthritis develops from an imbalance between anabolic and catabolic processes or homeostasis of cartilage metabolism [1,2]. The etiology of this disease is related to genetic association [3].

\footnotetext{
* Correspondence: tulyapruek@gmail.com

'Department of Orthopedics, Faculty of Medicine, Ramathibodi Hospital,

Mahidol University, Bangkok 10400, Thailand

Full list of author information is available at the end of the article
}

Recently, several studies have demonstrated the polymorphism in many genes which might be related to the pathogenesis of osteoarthritis [4-14]. Growth Differentiation Factor 5 or GDF5 gene regulates the expression of the GDF5 protein which is closely related to BMP and is a member of TGF-beta superfamily [15]. It has a role in regulation of the chondrogenesis and the defect in this gene might be correlated to the abnormal joint development [15]. It has been reported in animal study 
that GDF5 knockout mice develops knee joint anomaly [16]. Moreover, it has been shown that he polymorphism in GDF5 gene is related with low expression of the GDF5 protein in knee joint [17].

The large scale analysis has shown that the association of this polymorphism ( $r$ 143383) in promoter area might be a risk factor of the osteoarthritis [18]. In addition, studies of this genetic variant in China and Japan have shown the association of $\mathrm{T}$ allele and knee OA [19]. However, there is a report from Greece which had an inconsistent result and found no an association [20]. The genetic susceptibility of the disease in different ethnic cannot be applied to others because each ethnic has a different genetic background. There is a gap of information about this polymorphism in Thai population, therefore the objective of this study is to determine the association of the SNP rs143383 in GDF5gene and knee OA in Thai population.

\section{Patients and Methods Subjects}

Our study was approved by the Ethics Committee of the Faculty of Medicine, Ramathibodi Hospital, Mahidol University, Bangkok, Thailand. All patients recruited in the study were Thai by nationality and had ancestors settled in Thailand for at least three generations. In total, 90 patients with knee OA who underwent total knee arthroplasty (TKA) and 103 patients without knee OA were enrolled from Department of Orthopedics, Ramathibodi Hospital. Informed consent was performed after the purpose of the research project and it had been clearly explained to the patients. The diagnosis of knee OA was based on the American College of Rheumatology criteria [21]. Both OA and control groups were interviewed to obtain demographic data and all of established risk factors. Thereafter, standard weightbearing antero-posterior and lateral view of knee radiographs were taken to confirm the diagnosis of OA by Kellgren and Lawrence scores (KL scores) [22].

\section{Laboratory technique}

PCR-RFLP for BsiEl restriction site was used for SNP in GDF5 identification

Firstly, $5 \mathrm{ml}$ peripheral blood sample was collected from patient using ethylenediamine tetraacetic acid as an anticoagulant and processed for SNP analysis. Genomic DNA was extracted from buffy coat leukocytes using the standard phenol-chloroform method. PCR primers to amplify the promoter area of GDF5 gene were designed by the Primer-3 web-based tool [23]: GATTTTTTCTGAGCACCTGCAGG (forward) and GTGTGTGTT TGTATCCAG (reverse). $50 \mu \mathrm{l}$ PCR mixture contained $100 \mathrm{ng}$ of genomic DNA, $20 \mathrm{pmol}$ of each primer, $0.2 \mu$ $M$ of each dNTP, 1 unit of Taq DNA polymerase
(AmpliTaq ${ }^{\circledR}$, Applied Biosystem, Foster City, CA), 3.0 $\mathrm{mM} \mathrm{MgCl} 2$ in $10 \times$ PCR buffer containing $10 \mathrm{mmol}$ of Tri- $\mathrm{HCl} \mathrm{pH} \mathrm{9.0,} 10 \mathrm{mmol} \mathrm{KCl}$ and $0.1 \%$ Triton X-100 (Invitrogen, Carlsbad, CA). PCR reaction was started with an initial denaturation at $95^{\circ} \mathrm{C}$ for $5 \mathrm{~min}$, followed by 35 cycles of amplification in a thermocycler (PCR Sprint, Thermofisher, Waltham, MA) with denaturation at $94^{\circ} \mathrm{C}$ for $1 \mathrm{~min}$, annealing at $58^{\circ} \mathrm{C}$ for $1 \mathrm{~min}$, extension at $72^{\circ} \mathrm{C}$ for $1 \mathrm{~min}$, and final extension at $72^{\circ} \mathrm{C}$ for $10 \mathrm{~min}$. Then, $10 \mu \mathrm{L}$ of PCR product was incubated at $37^{\circ} \mathrm{C}$ with 3 units of BsiEI for 4 hours under the manufacturer's recommended conditions (New England Biolabs, Ipswich, MA). The digested product was electrophoresed on $2 \%$ agarose gel with ethidium bromide staining before being visualized on a UV transilluminator (Figure 1). The expected fragment length was 104 and $230 \mathrm{bp}$ in CC, 104, 230, and 344 bp in TC, and $344 \mathrm{bp}$ in TT genotypes, respectively.

\section{Statistical analyses}

Analysis of demographic data was performed by Excel 2007 (Microsoft $^{\circledR}$ Excel $^{\circledR}$ ). The unpaired t-test was used for continuous data and Chi-square was used for categorical data. Allele frequencies, Odds ratio and the probability for Hardy-Weinberg Equilibrium were estimated and analyzed as explained by following website; http:// ihg.gsf.de/cgi-bin/hw/hwa1.pl.

\section{Results}

In our study, the average age of patients in the knee OA group was significant older than in the control. BMI which is one of the risk factor of knee OA was also slightly higher in the OA patient group. However, other

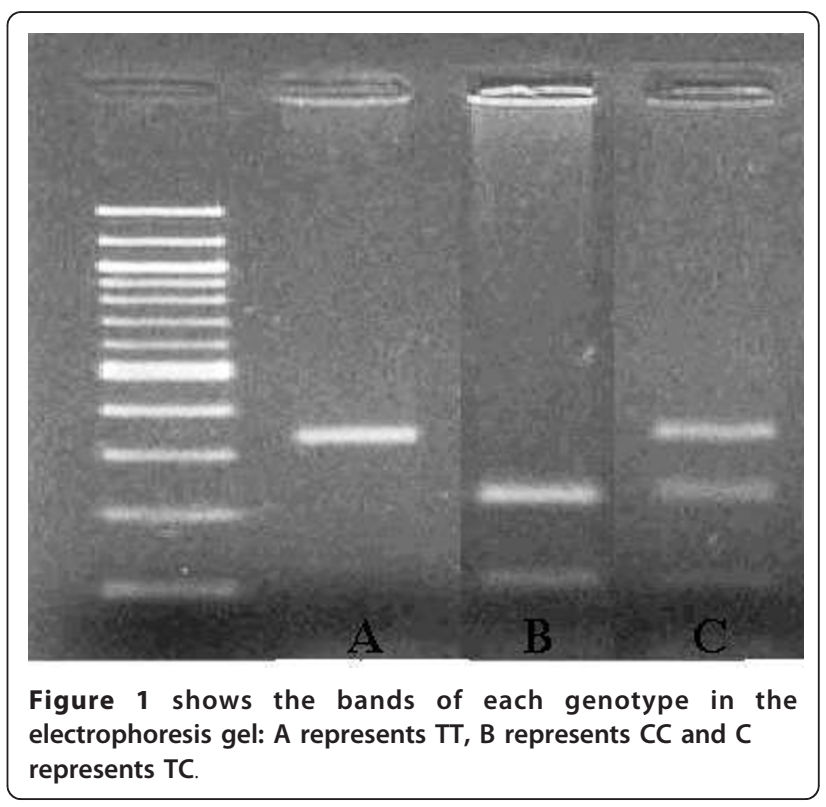


possible risk factors which might be related to OA as well as patient life style were comparable between these two groups. The baseline characteristics of the patients are shown in Table 1 . The prevalence of allele $\mathrm{T}$ and $\mathrm{C}$ in our sample was normally distributed according to the Hardy-Weinberg Equilibrium ( $\mathrm{p}$-value $<0.05$ ). The comparison of the number and odd ratio of genotype TT, $\mathrm{TC}$, TT+TC with $\mathrm{CC}$ of GDF5 polymorphism (rs143383) in the promoter area between case and control is demonstrated in Table 2. When analyzing by allele (shown in table 3), the odds ratio of $\mathrm{T}$ allele was $1.53(95 \%$ C.I. $=1.01-2.31)$, which delineated the increase in risk to develop knee OA. Our result shown that this polymorphism, $\mathrm{T} / \mathrm{C}$, is inherited by autosomal recessive manner as the TT genotype increases risk of the disease significantly $(\mathrm{OR}=2.41,95 \%$ C.I. $=1.02-5.67)$, whereas the TC has no significant difference.

\section{Discussion and Conclusion}

Our study has shown the statistically significant association between polymorphism in promoter of GDF5 gene (rs143383) and knee osteoarthritis in Thai population. We found that $\mathrm{T}$ allele in GDF5 polymorphism was a significant risk factor for knee osteoarthritis with Odds ratio $1.53(95 \%$ C.I. $=1.01-2.31)$. When analysed by genotype, it was found that the TT genotype increased risk of knee OA, whereas TC has not shown any correlation. Regarding these finding, it suggests that this polymorphic gene might be expressed as the autosomal recessive type. The GDF5 gene is located on the chromosome $20 \mathrm{q} 11.2$ and it regulates the expression of GDF5 protein. It is categorised in the class of bone morphogenetic protein (BMP) [15]. It involves in development of bone and cartilage, particularly in endochondral ossification process $[24,25]$. The mutation of GDF5 associates with generalised osteoarthritis and skeletalrelated congenital diseases. Acromesomelic chondrodysplasia; Grebe type and Hunter-Thompson type is

Table 1 Shows the base line characteristics between cases and controls

\begin{tabular}{lccc}
\hline \multicolumn{1}{c}{ Variables } & $\begin{array}{c}\text { Cases } \\
(\mathbf{n}=103)\end{array}$ & $\begin{array}{c}\text { Control } \\
(\mathbf{n}=103)\end{array}$ & p-value \\
\hline Age (years), mean (SD) & $68.46(10.0)$ & $59.25(9.0)$ & $<0.01^{*}$ \\
Onset of disease (years), mean (SD) & $61.46(9.06)$ & $\mathrm{N} / \mathrm{A}$ & $\mathrm{N} / \mathrm{A}$ \\
Female (\%) & $79(87.25)$ & $93(90.29)$ & 0.7 \\
BMI (kg/m²), mean (SD) & $26.66(4.0)$ & $24.57(5.0)$ & $<0.01^{*}$ \\
History of labor work (\%) & $25(27.78)$ & $30(29.13)$ & 0.20 \\
Regular exercise (\%) & $10(11.11)$ & $13(12.62)$ & 0.15 \\
Kneeling activity (\%) & $37(41.11)$ & $48(46.60)$ & 0.07 \\
Previous any fracture (\%) & $9(10.0)$ & $13(12.62)$ & 0.15 \\
Smoking (\%) & $2(2.22)$ & $4(3.88)$ & 0.10 \\
\hline
\end{tabular}

Note: *statistically significant, SD = standard deviation, N/A = not applicable
Table 2 Shows the association between each genotype and risk of knee $O A$

\begin{tabular}{ccccc}
\hline Genotype & $\begin{array}{c}\text { Case } \\
(\mathbf{n}=\mathbf{9 0})\end{array}$ & $\begin{array}{c}\text { Control } \\
(\mathbf{n}=\mathbf{1 0 3})\end{array}$ & $\begin{array}{c}\text { Odds ratio } \\
(\mathbf{9 5} \% \mathbf{C l})\end{array}$ & $\mathbf{p}$-value \\
\hline$T \mathrm{~T}$ & 38 & 33 & $2.41(1.022-5.670)$ & $0.04^{*}$ \\
$\mathrm{TC}$ & 41 & 47 & $1.82(0.794-4.190)$ & 0.15 \\
$\mathrm{TT}+\mathrm{TC}$ & 79 & 80 & $2.07(0.944-4.517)$ & 0.06 \\
$\mathrm{CC}$ & 11 & 23 & 1 & $\mathrm{~N} / \mathrm{A}$ \\
\hline
\end{tabular}

(CC was used for calculation Odd ratio of $\Pi$, $T C$ and $\Pi+T C$ )

Notes: ${ }^{*}$ statistically significant, N/A = not applicable

autosomal recessive form which is rare hereditary skeletal disorders. They are presented by short status, abnormal limbs development. Brachydactyly type A1, A2 and $\mathrm{C}$ and symphalangism proximal syndrome are inherited malformation presented with abnormal morphology of hand and finger. Multiple synostoses syndrome type 2 is an autosomal dominant condition characterised by progressive joint fusions and progressive conductive deafness. Du Pan syndrome is a rare autosomal recessive; the patient presents with absence of the fibulae and severe acromesomelic limb shortening with small, nonfunctional toes. These abnormal conditions have been reported that they have a mutation in GDF5 gene, thus they support that GDF5 plays a role in skeletal development $[26,27]$. Recently, it has been reported that GDF5 deficiency mice had the delay fracture healing process that impaired the cartilaginous matrix deposition in the callus and reduced callus cross-sectional area [28].

The functional study of this polymorphism has been demonstrated; $\mathrm{T}$ allele in rs143383 was associated with the decrease of GFD5 molecule expression and might increase susceptibility to osteoarthritis [17]. Moreover, it has been report that the differential binding of deformed epidermal autoregulatory factor 1 (DEAF-1) can modulate the expression of GDF5 via this polymorphism [29]. It is believed that GDF5 plays role in the regulation of the chondrogenic cell growth and differentiation. These evidences support the function of GDF5 gene which might indicate the importance of this polymorphism in osteoarthritis etiology. As the result, many scientists have been working for study the association of this polymorphism in GDF5 gene. Recently, a large scale association study between GDF5 gene and osteoarthritis has revealed the genetic susceptibility of polymorphism in

Table 3 Shows the association between allele and knee OA

\begin{tabular}{ccccc}
\hline Allele & Case & Control & Odds ratio $(\mathbf{9 5} \% \mathrm{Cl})$ & $\mathbf{p}$-value \\
\hline $\mathbf{T}$ & 117 & 113 & $1.53(1.013-2.306)$ & $0.04^{*}$ \\
$\mathbf{C}$ & 63 & 93 & 1 & $\mathrm{~N} / \mathrm{A}$
\end{tabular}

(C was used for calculation Odd ratio of $\mathrm{T}$ )

Notes: *statistically significant, N/A = not applicable 
the GDF5; rs143383 with odds ratio 1.12 (95\%CI 0.99 1.31) [18]. This study included the data from diverse ethnics which have been reported in the recent literatures. However, the magnitude of this association is smaller than the Asian ethnic, it has been reported from Japan that odds ratio is $1.79(\mathrm{P}=1.18 \times 10-13)$ for GDF5 polymorphism with per-risk allele (T) odds ratio by Miyamoto et al [17]. The magnitude of the association of GDF5 polymorphism is different between Caucasian ethnic and Asian ethnic. Furthermore, the association of this polymorphism from Greek and Korean study cannot demonstrate the association of GDF5 polymorphism $[20,30]$. We have also reported the polymorphism in ESR1, which is associated with knee OA in Korean population. However, our result did not show any statistically significant difference [31]. Thus, these evidences can imply that the association of ethic and genetic susceptibility in osteoarthritis might not be consistent among the different populations and cannot be applied to others.

In addition, there is a report that GDF5 polymorphism (rs143383) also predisposes to Lumbar disc degeneration in women. Lumbar disc degeneration which is defined by disc space narrowing and the presence of osteophytes significantly associates with GDF5 polymorphism from cohorts from Northern Europe in women, with an odds ratio (OR) of 1.72 (95\% CI 1.15-2.57) [32]. The genomewide association study from Finland and Sardinia shows the common variants in GDF5 contribute to height difference [33]. The GDF5 gene might be involved skeletal growth and development and GDF5 variants might play role in pathogenesis of bone and cartilage diseases.

Although the sample size in our study was small when compared to previous studies, these limited samples were sufficient for demonstrating the statistically significant association of $r s 143383$ in GDF5 core promotor area. Furthermore, the population in our study was in homogeneity and the distribution between the case and control groups was in the Hardy Weinberg's equilibrium. Therefore, our study can represent the significant susceptibility of GDF5 in knee osteoarthritis in Thai ethnic. Our findings have emphasized this association that the susceptibility of the polymorphism in GDF5 among the Asian population because the magnitude of association is close to Japan and Chinese population. It is possible that Thai population ethnic is believed to be close to Chinese ancestry. Finally, we decide to leave some suggestions in genetic susceptibility study. Firstly, it is important to study the genetic susceptibility in common disease as this might be valuable for further investigation in order to understand the disease at molecular level or even apply to use for disease screening. More important, the association between polymorphism and disease might not similar in different ethics; therefore the genetic susceptibility from different ethics is required and the meta-analysis should be conducted in the adjacent area or similar genetic background. Lastly, other modern technology such as microarray technique should be employed for investigation of genetic susceptibility in osteoarthritis.

\section{Acknowledgements and Funding}

This work was supported by grants from the biomedical research fund (\#50039) of Faculty of Medicine, Ramathibodi Hospital, Bangkok, Thailand.

\section{Author details}

'Department of Orthopedics, Faculty of Medicine, Ramathibodi Hospital, Mahidol University, Bangkok 10400, Thailand. 'Division of Medical Genetics and Molecular Medicine, Department of Medicine, Faculty of Medicine, Ramathibodi Hospital, Mahidol University, Bangkok 10400, Thailand.

\section{Authors' contributions}

$\Pi$ conducted the acquisition, analysis and interpretation of data, carried out the molecular genetic studies and drafted the manuscript. TC collected data. SP carried out the genetic study; RFLP. OT participated in the design of the study and performed the statistical analysis. TS and WW participated in its design and coordination and helped to draft the manuscript. All authors read and approved the final manuscript.

\section{Competing interests}

The authors declare that they have no competing interests.

Received: 27 March 2011 Accepted: 21 September 2011 Published: 21 September 2011

\section{References}

1. Felson DT: Osteoarthritis of the knee. N Engl J Med 2006, 354:841-8

2. Sandell $L$, Aigner $T$ : Articular cartilage and changes in arthritis. An introduction: cell biology of osteoarthritis. Arthritis Res 2001, 3:107-13.

3. Lanyon P, Muir K, Doherty S, Doherty M: Assessment of a genetic contribution to osteoarthritis of the hip: sibling study. BMJ 2000, 321:1179-83.

4. Loughlin J, Sinsheimer JS, Mustafa Z, Carr AJ, Clipsham K, Bloomfield VA, Chitnavis J, Bailey A, Sykes B, Chapman : Association analysis of the vitamin $D$ receptor gene, the type I collagen gene $C O L 1 A 1$, and the estrogen receptor gene in idiopathic osteoarthritis. J Rheumatol 2000, 27:779-84

5. Spector TD, MacGregor AJ: Risk factors for osteoarthritis: genetics. Osteoarthritis Cartilage 2004, 12(Suppl A):39-44

6. Smith AJ, Keen LJ, Billingham MJ, Perry MJ, Elson CJ, Kirwan JR, Sims JE, Doherty M, Spector TD, Bidwell JL: Extended haplotypes and linkage disequilibrium in the IL1R1-IL1A-IL1B-IL1RN gene cluster: association with knee osteoarthritis. Genes Immun 2004, 5:451-60.

7. Aigner T, Dudhia J: Genomics of osteoarthritis. Curr Opin Rheumatol 2003 15:634-40

8. Kizawa $H$, Kou I, lida A, Sudo A, Miyamoto Y, Fukuda A, Mabuchi A, Kotani A, Kawakami A, Yamamoto S, Uchida A, Nakamura K, Notoya K, Nakamura Y, Ikegawa S: An aspartic acid repeat polymorphism in asporin inhibits chondrogenesis and increases susceptibility to osteoarthritis. Nat Genet 2005, 37:138-144.

9. Mabuchi A, Ikeda T, Fukuda A, Koshizuka Y, Hiraoka H, Miyoshi K, Haga N, Kawaguchi H, Kawakami A, Yamamoto S, Takatori Y, Nakamura K, Ikegawa S: Identification of sequence polymorphisms of the COMP (cartilage oligomeric matrix protein) gene and association study in osteoarthrosis of the knee and hip joints. J Hum Genet 2001, 46:456-462.

10. Mototani H, Mabuchi A, Saito S, Fujioka M, lida A, Takatori Y, Kotani A, Kubo T, Nakamura K, Sekine A, Murakami Y, Tsunoda T, Notoya K, Nakamura $Y$, Ikegawa S: A functional single nucleotide polymorphism in the core promoter region of CALM1 is associated with hip osteoarthritis in Japanese. Hum Mol Genet 2005, 14:1009-1017.

11. Ikeda T, Mabuchi A, Fukuda A, Hiraoka H, Kawakami A, Yamamoto S, Machida H, Takatori Y, Kawaguchi H, Nakamura K, Ikegawa S: Identification 
of sequence polymorphisms in two sulfation-relatedgenes, PAPSS2 and SLC26A2, and an association analysis with knee osteoarthritis. J Hum Genet 2001, 46:538-543.

12. Jiang Q, Shi D, Yi L, Ikegawa S, Wang Y, Nakamura T, Qiao D, Liu C, Dai J: Replication of the association of the aspartic acid repeat polymorphism in the asporin gene with knee-osteoarthritis susceptibility in Han Chinese. J Hum Genet 2006, 51:1068-1072.

13. Valdes AM, Spector TD: The contribution of genes to osteoarthritis. Rheum Dis Clin North Am 2008, 34:581-603.

14. Valdes AM, Loughlin J, Timms KM, van Meurs JJ, Southam L, Wilson SG, Doherty S, Lories RJ, Luyten FP, Gutin A, Abkevich V, Ge D, Hofman A, Uitterlinden AG, Hart DJ, Zhang F, Zhai G, Egli RJ, Doherty M, Lanchbury J, Spector TD: Genome-wide association scan identifies aprostaglandinendoperoxide synthase 2 variant involved in risk of knee osteoarthritis. Am J Hum Genet 2008, 82:1231-4.

15. Buxton P, Edwards C, Archer CW, Francis-West P: Growth/differentiation factor-5 (GDF-5) and skeletal development. J Bone Joint Surg Am 2001, 83-A(Suppl 1):23-30.

16. Harada M, Takahara M, Zhe P, Otsuji M, luchi Y, Takagi M, Ogino T: Developmental failure of the intra-articular ligaments in mice with absence of growth differentiation factor 5. Osteoarthritis Cartilage 2007, 15:468-74.

17. Miyamoto Y, Mabuchi A, Shi D, Kubo T, Takatori Y, Saito S, Fujioka M, Sudo A, Uchida A, Yamamoto S, Ozaki K, Takigawa M, Tanaka T, Nakamura Y, Jiang Q, lkegawa S: A functional polymorphism in the 5'-UTR of GDF5 is associated with susceptibility to osteoarthritis. Nat Genet 2007, 39:529-33.

18. Evangelou E, Chapman K, Meulenbelt l, et al: Large-scale analysis of association between GDF5 (rs143383) and FRZB (rs7775 and rs288326) variants and hip, knee and hand osteoarthritis. Arthritis Rheum 2009, 60:1710-1721.

19. Chapman K, Takahashi A, Meulenbelt I, Watson C, Rodriguez-Lopez J, Egli R, Tsezou A, Malizos KN, Kloppenburg M, Shi D, Southam L, van der Breggen R, Donn R, Qin J, Doherty M, Slagboom PE, Wallis G, Kamatani N, Jiang Q, Gonzalez A, Loughlin J, Ikegawa S: A meta-analysis of European and Asian cohorts reveals a global role of a functional SNP in the $5^{\prime}$ UTR of GDF5 with osteoarthritis susceptibility. Hum Mol Genet 2008, 17:1497-504.

20. Tsezou A, Satra M, Oikonomou P, Bargiotas K, Malizos KN: The growth differentiation factor 5 (GDF5) core promoter polymorphism is not associated with knee osteoarthritis in the Greek population. J Orthop Res 2008, 26:136-40

21. Altman R, Asch E, Bloch D, Bole G, Borenstein D, Brandt K, Christry W, Cooke TD, Greenwald R, Hochberg M, Howell D, Kaplan W, Koopman T, Meenan R, Maskowitz R, Murphy W, Rothschild B, Segal M, Sokoloff L, Wolfe F: Development of criteria for the classification and reporting of osteoarthritis: classification of osteoarthritis of the knee. Diagnostic and Therapeutic Criteria Committee of the American Rheumatism Association. Arthritis Rheum 1986, 29:1039-49.

22. Kellgren JK, Lawrence JS: Radiological assessment of osteoarthritis. Ann Rheum Dis 1957, 16:494-501.

23. Rozen S, Skaletsky HJ: Primer3 on the WWW for general users and for biologist programmers. In Bioinformatics Methods and Protocols: Methods in Molecular Biology 2000. Edited by: Krawetz S, Misener S Totowa. NJ: Humana Press; 2000:365-86.

24. Francis-West PH, Abdelfattah A, Chen P, Allen C, Parish J, Ladher R, Allen S, MacPherson S, Luyten FP, Archer CW: Mechanisms of GDF-5 action during skeletal development. Development 1999, 126(6):1305-15.

25. Hatakeyama Y, Tuan RS, Shum L: Distinct functions of BMP4 and GDF5 in the regulation of chondrogenesis. J Cell Biochem 2004, 91:1204-17.

26. Thomas JT, Lin K, Nandedkar M, Camargo M, Cervenka J, Luyten FP: A human chondrodysplasia due to a mutation in a TGF-b superfamily member. Nat Genet 1996, 12(3):315-7.

27. GDF5 growth differentiation factor 5 [Homo sapiens ]. [http://www.ncbi. nlm.nih.gov/sites/entrez?Db=gene\&Cmd=ShowDetailView\&TermToSearch = 8200].

28. Coleman CM, Scheremeta BH, Boyce AT, Mauck RL, Tuan RS: Delayed fracture Healing in growth differentiation factor 5-deficient mice: A pilot study. Clin Orthop Relat Res.

29. Egli RJ, Southam L, Wilkins JM, Lorenzen I, Pombo-Suarez M, Gonzalez A Carr A, Chapman K, Loughlin J: Functional analysis of the osteoarthritis susceptibility-associated GDF5 regulatory polymorphism. Arthritis Rheum 2009, 60:2055-64.

30. Cao Z, Lee HS, Song JH, Yoon JW, Park YK, Nam SW, Lee JY, Park WS: Growth Differentiation Factor 5 (GDF5) core promoter polymorphism is not associated with susceptibility to osteoarthritis of the knee in the Korean population. Korean J Pathol 2010, 44:404-9.

31. Tawonsawatruk T, Trachoo O, Channoom T, Sura T, Eu-ahsunthornwattana J, Woratanarat P, Wajanavisit W: Association of Estrogen Receptor-alpha single-nucleotide polymorphism (codon $594 \mathrm{G} / \mathrm{A}$ ) and Thai patients affected by knee osteoarthritis. J Med Assoc Thai 2009, 92(Suppl 6):45-50.

32. Williams FM, Popham M, Hart DJ, de Schepper E, Bierma-Zeinstra S, Hofman A, Uitterlinden AG, Arden NK, Cooper C, Spector TD, Valdes AM, van Meurs J: GDF5 single-nucleotide polymorphism rs 143383 is associated with lumbar disc degeneration in Northern European women. Arthritis Rheum 2011, 63(3):708-12.

33. Sanna S, Jackson AU, Nagaraja R, Willer CJ, Chen WM, Bonnycastle LL, et al: Common variants in the GDF5-UQCC region are associated with variation in human height. Nat Genet 2008, 40(2):198-203.

doi:10.1186/1749-799X-6-47

Cite this article as: Tawonsawatruk et al:: A genetic association study between growth differentiation factor 5 (GDF 5) polymorphism and knee osteoarthritis in Thai population. Journal of Orthopaedic Surgery and Research 2011 6:47.

\section{Submit your next manuscript to BioMed Central and take full advantage of:}

- Convenient online submission

- Thorough peer review

- No space constraints or color figure charges

- Immediate publication on acceptance

- Inclusion in PubMed, CAS, Scopus and Google Scholar

- Research which is freely available for redistribution

Submit your manuscript at www.biomedcentral.com/submit
Ciomed Central 